\title{
SOLOS REFORÇADOS COM GEOSSÍNTETICOS: OBRAS DE CONTENÇÕES DE ATERROS DE PONTES E VIADUTOS
}

\section{SOILS REINFORCED WITH GEOSSYTHETICS: CONSTRUCTION WORKS OF BRIDGE AND VIADUES}

Barbara Florrance de Melo Rocha, Beatriz de Mello Massimino

Universidade do Oeste Paulista - UNOESTE.

E-mail: barbaraflorrance@hotmail.com

RESUMO - O trabalho apresenta o emprego da técnica de obras com contenção de solos em aterros reforçados com geossintéticos em pontes e viadutos, com o objetivo de realizar a análise da viabilidade e aplicação do método, realizar o levantamento de obras executadas no Brasil e verificar as propriedades mecânicas atuantes. Conclui-se que a utilização de geossintéticos de alta resistência, alto módulo e baixa fluência, aliados a uma compactação energética resultam em estruturas pouco deformáveis, que atendem aos requisitos de aspecto estético e funcionalidade, além de segurança ao colapso nessas obras, e apresenta-se como alternativa de grande flexibilidade construtiva e rápida execução, tornando-se de custo relativamente baixo em comparação aos métodos de construções tradicionais.

Palavras-chave: Aterros Reforçados, Geossintéticos, Obras de Contenção.

ABSTRACT - This work presents the use of soil retention techniques in landfills reinforced with geosynthetics in bridges and viaducts, with the objective of carrying out the feasibility analysis and application of the method, carrying out the survey of works carried out in Brazil and verifying the mechanical properties acting. It is concluded that the use of geosynthetics of high strength, high modulus and low creep, combined with energy compaction results in structures that are not deformable, that meet the requirements of aesthetic appearance and functionality, as well as safety to collapse in these works, as an alternative of great constructive flexibility and fast execution, making it relatively low cost compared to traditional construction methods.

Keywords: Reinforced embankments, Geosynthetics, Containment Works. 


\section{INTRODUÇÃO}

Em meados de 1970, com o desenvolvimento de geossintéticos (geotêxtis não tecido e geogrelhas), remonta-se as primeiras técnicas de reforço de aterros sobre solos moles e taludes (RUIZ et al., 2018).

No Brasil surgiram na década de 80 , as primeiras obras de solo reforço, que utilizavam de técnicas muito simples de solo envelopado com reforço de compostos por geotêxteis onde o paramento frontal deveria receber concreto projetado ou outras proteções e foram amplamente utilizadas em todas as regiões do país (ANANIAS et al., 2013).

Atualmente, a técnica de solo mecanicamente estabilizado (Mechanically Stabilized Earth - MSE), apresenta-se como alternativa mais econômica e de fácil execução, quando comparada à estruturas tradicionalmente empregadas, quanto a contenção de gravidade e estruturas de concreto armado (RUIZ et al., 2018). A Figura 1 apresenta um comparativo entre obras tradicionais e com método de solo reforçado.

Figura 1. Comparativo de soluções de contenção (tradicional x muro com geossintéticos).
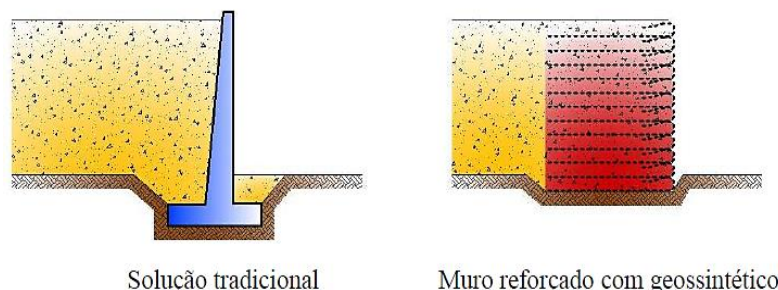

Muro reforçado com geossintéticos

Fonte: Ruiz et al., (2018).

A utilização de estruturas em solo reforçado é uma tecnologia de grande importância para projetos de contenção. Inclusões em obras geotécnicas, possuem a intenção de reforçar a resistência à tração, alterando as características internas dos solos nos quais são inseridos, são muito usadas para a contenção ou estabilização de taludes e aterro e são chamadas de estruturas de solos reforçados (MAPARAGEM, 2017).

Entre as características dos solos reforçados, destaca-se o uso de materiais e do solo local, a possibilidade de execução de taludes mais íngremes, a facilidade de execu- ção de obras em locais de difícil acesso, o apoio sobre solo natural e não necessidade de execução de fundações específicas (ANANIAS et al., 2013).

As primeiras obras de artes (pontes e viadutos) com a aplicação técnica especificas de solo reforçado surgem seguindo o conceito tradicional de projeto e especificações de reforços que já eram utilizados, executando muros de contenções das alas e ombreiras laterais dos encontros. A superestrutura era apoiada sobre infraestruturas (estacas) independentes, não sendo apoiadas diretamente no corpo do aterro compactado. A única carga que atuava sobre os reforços seria de empuxos ativos do maciço de solo. Sob o ponto de vista da condição de serviços, para que não ocorressem deslocamentos diferenciais acentuados entre a infra e superestrutura, os reforços deviam ser dimensionados para resistir aos empuxos, garantido baixa deformação na estrutura (RUIZ et al., 2018).

Com o passar do tempo, devido ao desenvolvimento de novos geossintéticos, técnicas de execução, pesquisa e conhecimento do comportamento em obras, proporcionaram a possibilidade do total controle do desempenho destas obras, e diversas alternativas para cada necessidade (ANANIAS et al., 2013).

A partir destes conceitos e técnicas, surgem os projetos onde o tabuleiro (superestrutura), apoia-se diretamente sobre aterros reforçados, devido a inúmeras características e vantagens de métodos de solo reforçado, bem como os aspectos estimados importantes para o dimensionamento e execução, considerados como encontros portantes em obras rodoviárias e urbanas.

\section{OBJETIVOS}

\subsection{Objetivo Geral}

O emprego da técnica de obras com contenção de solos em aterros reforçados com geossintéticos utilizados na execução de pontes e viadutos devido a vantagens de fatores técnicos e econômicos. 


\subsection{Objetivos Específicos}

- Analise da técnica da viabilidade de reforço de aterros e os tipos de geossintéticos utilizados em estruturas de obras de pontes e viadutos.

- Levantamento de obras executadas através de encontros portantes em obras onde o tabuleiro (superestrutura), apoia-se diretamente sobre aterros reforçados.

- Verificação das propriedades mecânicas atuantes em obras de solos reforçados: tração, rigidez do reforço, deformação e servicibilidade.

\section{SOLOS REFORÇADOS COM GEOSSÍNTETI- COS EM CONTENÇÕES DE PONTES E VIADU- TOS}

\subsection{Históricos de Primeiros Projetos}

$\mathrm{Na}$ década de 90, foram executados os primeiros projetos que aproveitam a capacidade de carga dos aterros reforçados como apoio direto do tabuleiro de ponte (superestrutura). Neste caso, a estrutura de apoio se projeta com capacidade suficiente para suportar as correspondentes cargas verticais concentradas, com pressões da ordem de 150 a $250 \mathrm{kN} / \mathrm{m} 2$, em uma área limitada a menos de $2 \mathrm{~m}$ de largura, próximo da crista frontal do aterro de acesso (ALEXIEW et al., , apud2007RUIZ, 2018).

\subsubsection{Viaduto na Dinamarca}

Em 1992, próximo a cidade de Ullerslev, na Dinamarca, foi executado um dos projetos pioneiros em adotar reforço de solo, em um cruzamento em desnível da estrada sobre um tramo de ferrovia. $\mathrm{O}$ tabuleiro do Viaduto que possuía 15,50 metros de comprimento, foi apoiado diretamente sobre aterros reforçados, de 5,40 metros de altura livre. Foi projetado para suportar uma carga permanente pontual de 2000 kN e uma carga de tráfego de 1700 kN, sem mobilizar deformações expressivas (RUIZ et al., 2018). A Figura 2 apresenta a obra do viaduto em solo reforçado em Ullerslev, Dinamarca.
Figura 2. Viaduto em solo reforçado em Ullerslev, Dinamarca.

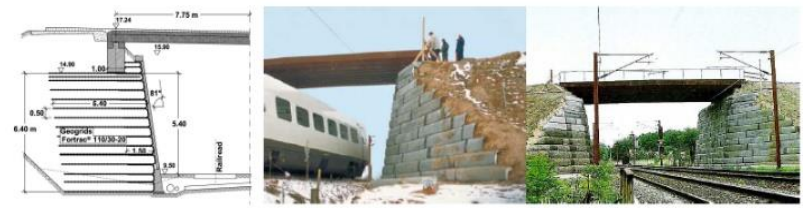

Fonte: Ruiz et al., (2018).

O comportamento geral desta estrutura foi considerado extremamente satisfatório, devido a dispositivos de medicação de deslocamentos horizontais que foram instalados na face, que ao longo do primeiro ano, registrou recalques por acomodação interna não superiores a $2 \mathrm{~mm}$ com o uso de solo reforçado (RUIZ et al., 2018).

\subsubsection{Ponte na Alemanha}

Por volta do ano 2000, foi construída uma ponte portante sobre o rio llse, na rodovia k1355 em Ilsenburg - Alemanha, projetada para atender a cargas maiores. Devido ao cumprimento satisfatório das exigentes normas técnicas alemãs, o sucesso desta obra motivou que a solução fosse considerada como perfeitamente aceitável desde então, em muitos países europeus (RUIZ et al., 2018). A Figura 3 apresenta a obra da ponte em solo reforçado em Ilsenburg, Alemanha.

Foi instalado um conjunto de dispositivos para instrumentação de controle, que verificaram valores de deformação vertical de 4 a $8 \mathrm{~mm}$, e deslocamentos horizontais de 1 a $2 \mathrm{~mm}$ (RUIZ et al., 2018).

Figura 3. Ponte em solo reforçado em Ilsenburg, Alemanha.

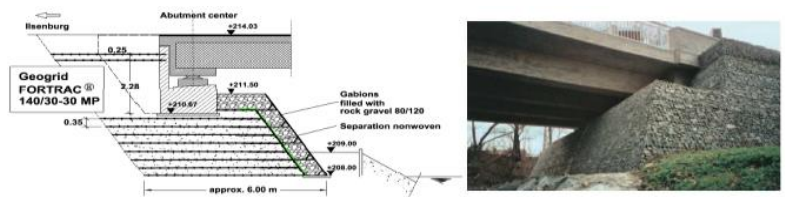

Fonte: Ruiz et al., (2018).

\subsection{Comparativos entre os métodos tradici-} onais e o de reforço

A aplicação de muros de solo reforçado com geossintéticos em encontros de pontes e viadutos, tem se desenvolvido, como apoio direto das estruturas de arte, sobre sua superfície, como alternativa de substitui- 
ção às estruturas tradicionais de contenção frontal ou muro de ala.

Sua principal vantagem consiste no fato de, por se tratar de uma estrutura flexível e deformável, esta se adapta muito bem a fundações sobre solos moles, ou mesmo em condições submersas, além de alternativa de construção considerada fácil e rápida (RUIZ et al., 2018). A Figura 4 apresenta comparativo entre obras de pontes e viadutos com métodos tradicionais e com método de solo reforçado.

Figura 4. Comparativo de soluções de contenção para encontros de viadutos e pontes (tradicional $x$ muro com geossintéticos).
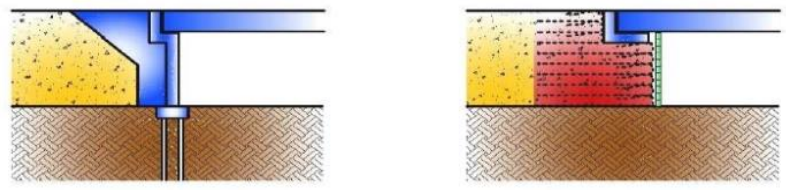

Fonte: Ruiz et al., (2018).

Comparado ao método tradicional, soluções de contenção para encontros de viadutos e pontes, a capacidade de suporte requerida é mais exigente e os deslocamentos ou deformações admitidas são muita mais limitadas (RUIZ et al., 2018).

Para vencer desníveis em aterros, a execução de solo reforçado usa o próprio solo como a estrutura de contenção, estabilização sua massa por meio de inclusões de comprimento e espaçamento variável (AVESANI NETO et al., 2013).

\subsection{Geometria, detalhes de projeto e cons- trutivos}

Os sistemas de reforço de solos em pontes ou viadutos são essencialmente compostos por três elementos que são: $O$ reforço, o material de preenchimento e a face.

\subsubsection{Reforço}

Os elementos de reforço são geralmente classificados como inextensíveis (metálicos) ou extensíveis (polímeros). Que são baseadas na deformação necessária para mobilizar toda a força do reforço em relação à deformação necessária para mobilizar toda a força do solo (MAPARAGEM, 2017).
Os reforços inextensíveis geralmente incluem aço e grades, por exemplo, estruturas em terra armada, solo grampeado e outras. Enquanto os reforços extensíveis incluem polímeros como geogrelhas e geotêxteis.

Com o emprego das geogrelhas de poliéster e PVA em substituição aos geotêxteis não tecidos e tecidos de polipropileno, as obras se tornaram menos deformáveis e a técnica hoje pode ser utilizada para praticamente qualquer aplicação, desde taludes naturais até encontros portantes de pontes e viadutos (BRUGGGER; MONTEZ, 2003). Caso deseja-se uma estrutura com deformações menores, há a alternativa de utilizar no projeto geogrelhas de poliéster, mas com níveis de tensão mobilizada mais baixos, utilizando reforços mais resistentes do que calculados para a ruptura. Diferente opção seria a utilização de geogrelhas de PVA, que proporcionam módulos de rigidez maiores do que as geogrelhas de poliéster.

Os reforços mais adequados atualmente para solo reforçado são geogrelhas fabricadas a partir de polímeros de poliéster ou PVA. Estas geogrelhas apresentam alto módulo de rigidez e baixa fluência, resultando em obras bastante rígidas após construção. Essa característica é particularmente importante se existirem estruturas rígidas como vias pavimentadas no topo dos muros. O projeto deve prever, além da segurança à ruptura, uma deformação adequada à utilização da obra. De modo geral procura-se projetar obras onde os reforços tenham alongamentos específicos típicos de 3 a 5\% (BS 8006), o que equivale a trabalhar com tipicamente $30 \%$ da resistência última de geogrelhas de Poliéster e $50 \%$ da resistência última de resistências de PVA. Além disso, deve ser feita uma compactação pesada, preferencialmente com $100 \%$ do ensaio proctor normal em todas as camadas, de modo a mobilizar os esforços nas geogrelhas durante o processo construtivo e assim minimizar deformações posteriores. Sugere-se utilizar para o dimensionamento métodos de cálculo que considerem os esforços induzidos pela com- 
pactação, como o método de Ehrlich e Mitchel, 1994 (BRUGGER; SILVA, 2009).

\subsubsection{Material de preenchimento}

O material de preenchimento é constituído por solos selecionados para a execução (MAPARAGEM, 2017).

$O$ material de aterro também pode ser utilizado de jazida próxima, desde que o solo atenda as condições mínimas especificadas em projetos.

O solo internacional reforçado é fortemente baseado na utilização de arenosos, enquanto no Brasil, tem mostrado que a utilização de solos mais finos que é perfeitamente aceitável e até com vantagens, principalmente quando são utilizados solos residuais saprolíticos. Esses solos apresentam ótimo comportamento mecânico quando bem compactados e são bastante rígidos, sendo que boa parte deste bom comportamento é devido à coesão aparente decorrente de sucção provocada pela compactação da massa de solo não saturada (BRUGGER; SILVA, 2009).

\subsubsection{Face}

Para Ruiz et al. (2018) a face do parâmetro frontal de um MSE com geossintéticos podem ser executados com total independência estrutural do maciço de contenção, em ampla variedade de faceamento, tais como: revestimento vegetal (hidrossemeadura), concreto projetado, painéis préfabricados, blocos segmentais ou muros autoportantes de alvenaria ou de pedra.

Para manter o sistema estável, com uma boa forma são construídos blocos em elementos pré-fabricados, que geralmente, consistem em painéis de concreto prémoldado ou blocos de alvenaria modular prémoldado ou ainda metálicos (MAPARAGEM, 2017).

A execução de face envelopada consiste em utilizar sacarias preenchidas com solo local, envelopados com geossintéticos, formando uma ancoragem do reforço da face, que pode ser revestida com vegetação ou concreto projetado, segundo Avesani Neto et al., (2013) considera-se camadas de 40 centímetros de espaçamento entre os geossintéticos de reforço. A seguir, a Figura 5 apresenta o modelo de Face envelopada.

Figura 5. Face envelopada, revestimento vegetal com utilização de espécies em trepadeira.

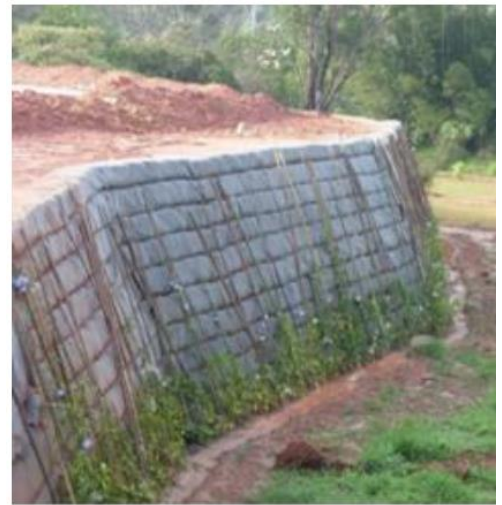

Fonte: AVESANI NETO, et al., (2013).

Face em blocos segmentais (Figuras 6 e 7) são utilizados na implantação de muros portantes em encontro de pontes e viadutos, mostra-se viável sob diversos aspectos: possuem ótimo acabamento estético, facilidade construtiva, boa adequação geométrica da estrutura. São preenchidos por brita e até mesmo pinos metálicos. De acordo com Avesani Neto et al., (2013) há uma redução no consumo de inclusões e um aumento tanto da produtividade como da estética do muro em relação ao faceamento envelopado.

Figura 6. Face de bloco segmentados, construção de um acesso transversal à rodovia Federal BR 101, no Rio Grande do Sul.

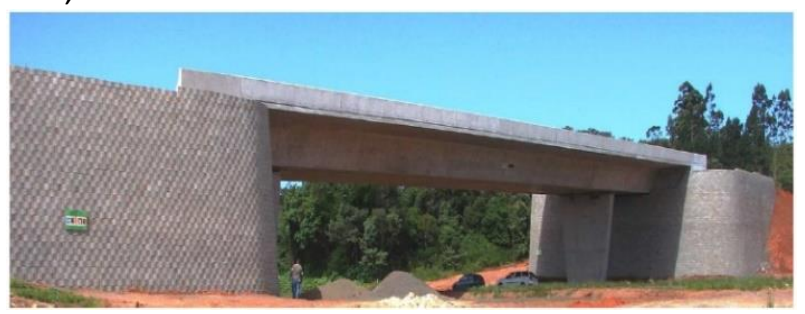

Fonte: Ruiz et al., (2018). 
Figura 7. Construção de um encontro em uma passagem inferior à rodovia BR 101, no Rio Grande do Sul, faceamento em blocos segmentados.

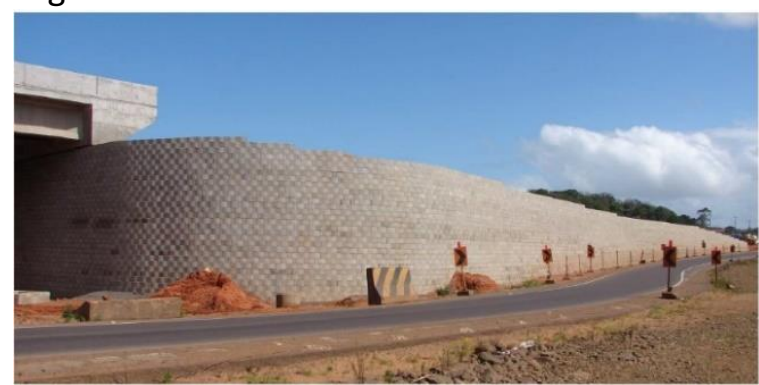

Fonte: Ruiz et al., (2018).

O sistema de faceamento prémoldados, por meio de painéis (Lock \& Lo$\mathrm{ad}^{\circledR}$ ) utiliza módulos de concreto estrutural reforçado com fibras. Este tipo de faceamento permite um maior espaçamento vertical do reforço, com valores de 80 e $120 \mathrm{~cm}$. Outra vantagem é a possibilidade de execução de muros de até $1,2 \mathrm{~m}$ de altura sem a necessidade de dispor de reforços (AVESANI NETO et al., 2013).

As figuras 8,9 e 10 a seguir, apresentam o método de contenção (além de reforço de solo com geossintéticos), em Faceamento em painéis moldados, obra do viaduto de acesso do Aeroporto Estadual de Presidente Prudente, na Rodovia Assis Chateaubriand (SP-425), em Presidente Prudente - SP.

Figura 8. Faceamento em painéis moldados, obra do viaduto de acesso do Aeroporto Estadual de Presidente Prudente, na Rodovia Assis Chateaubriand (SP-425), em Presidente Prudente - SP.

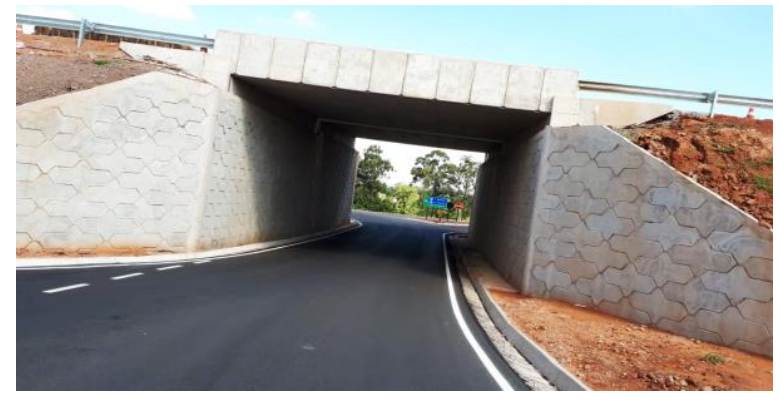

Fonte: Autor (2018).
Figura 9. Faceamento em painéis moldados, obra do viaduto de acesso do Aeroporto Estadual de Presidente Prudente.

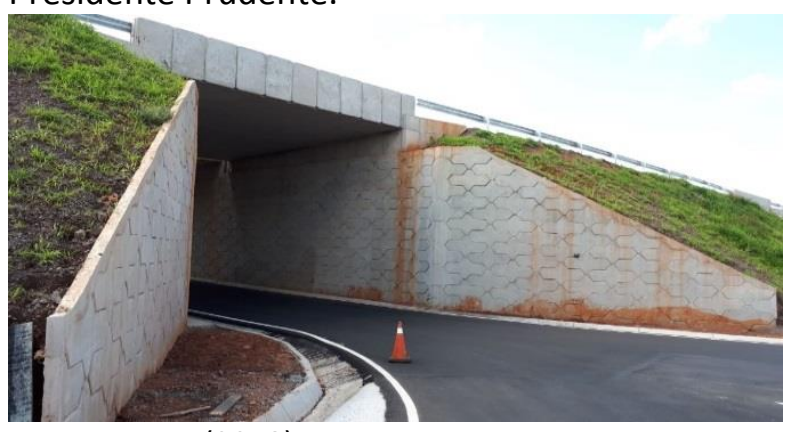

Fonte: Autor (2018).

A obra trata-se de um projeto que vem sendo executado visando melhorar as condições de trafegabilidade e segurança na rodovia Assis Chateaubriand em trecho de 22 quilômetros duplicados entre Presidente Prudente e Pirapozinho, no estado de São Paulo.

Há a possibilidade de uma elevada produtividade, atingindo velocidades de instalação de até $40 \mathrm{~m}^{2} /$ dia/equipe, obtendo um acabamento estético mais elevado se comparado com os outros 2 (dois) sistemas supracitados. Obtendo-se a vantagem de usar reforços de reduzida resistência, para camadas mais profundas e de maior espaçamento para camadas mais superficiais.

Figura 10. Face em painéis moldados, obra do contenção de acesso do Aeroporto Estadual de Presidente Prudente.

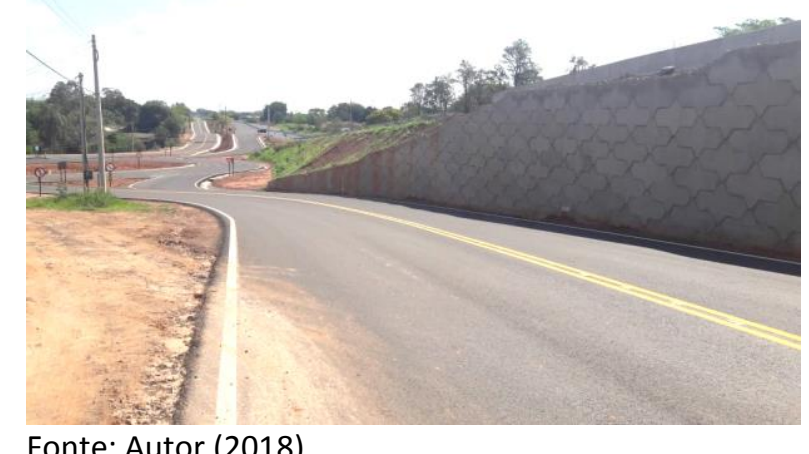

Fonte: Autor (2018).

Em uma análise de comparação de custo, realizada por Avesani Neto et al., (2013), a solução em solo reforçado com geossintéticos apresentou o menor custo para todas as alturas consideradas, especialmente a solução envelopada, pois esta não considera nenhum sistema de faceamento definitivo 
final. O faceamento com painéis prémoldados, apesar de ter um custo mais elevado da face, se mostra economicamente favorável, visto que as dimensões dos painéis permitem uma maior produtividade (três vezes maior que o envelopado), reduzindo o custo de execução. A face em bloco é a que se mostrou mais onerosa em relação às outras soluções com geossintéticos, pois, diferente do envelopado, é um sistema definitivo de faceamento com custo de material do bloco. Contudo, diferente também do painel, a dimensão do bloco é inferior (cerca de quatro vezes), motivo que faz com que sua produtividade não seja tão boa quanto o painel.

\subsubsection{Execução}

Para iniciar a execução da contenção em solo reforçado, é necessário a preparação do local com a retirada de quaisquer materiais que possam ser danosos aos reforços e fornecer a locação topográfica do alinhamento frontal da contenção (muro ou talude em solo reforçado) (ANANIAS et al., 2013).

Em seguida, os geossintéticos determinados em projeto deverão ser cortados de acordo com o comprimento estimado em projeto e esticado no terreno regularizado, podendo ser utilizados piquetes de madeira ou vergalhões, para fixar os geossintéticos no local para evitar a movimentação durante o lançamento do aterro. O sentido de maior resistência devera ficar perpendicular a face, pois são onde apresentam maiores esforços de tração (ANANIAS et al., 2013).

Deve-se lançar o material preenchimento (aterro de solo), em camadas compactadas, de acordo com as espessuras estimadas em projeto, evitando que o equipamento de compactação movimente o reforço. Geralmente, a compactação próxima a face da contenção na faixa de 1,00 metro, é executada com equipamentos considerados leves, de forma manual e evitando deformações do pareamento frontal. A área restante pode ser compactada com equipamentos mecânicos considerados pesados, desde que atendam as especificações do projeto a ser executado. Toda a etapa é repetida até que atinja a con- clusão do aterro ou reforço do solo estimado para a conclusão da obra.

\subsection{Propriedades Mecânicas}

\subsubsection{Resistência à tração}

A técnica de reforço de solo consiste em melhorar o solo conferindo-lhe a capacidade de resistência a tração (MAPARAGEM, 2017).

A introdução de reforços traz ao maciço a ser estabilizado um comportamento mecanicamente mais favorável, pois, quando as inclusões resistentes a tração é convenientemente inserida promovem uma redistribuição de esforços nas zonas mais susceptíveis a movimentação, tornando o sistema resistente e estável; assim, as estruturas de solo reforçado são mais resistentes e menos deformáveis (MAPARAGEM, 2017).

Quando o solo recebe um carregamento vertical, ocorrem deformações verticais de compressão e deformações laterais de extensão (tração). Contudo, se o solo estiver reforçado, os movimentos laterais são limitados pela reduzida deformabilidade do reforço. Esta restrição de deformações é obtida graças ao desenvolvimento de esforços de tração no elemento de reforço. Neste caso, o solo tende a mover-se em relação ao reforço gerando tensões cisalhantes na interface (WHEELER, 1996, apud MAPARAGEM, 2017).

A Figura 11 a seguir ilustra o princípio básico do comportamento do método de solo reforçado, onde evidencia o comparativo do comportamento do solo sem e com o reforço em geossintético, devido a forças atuantes de tração e deformação.

Figura 11. Comportamento típico do solo: (a) sem reforço; e (b) com reforço.

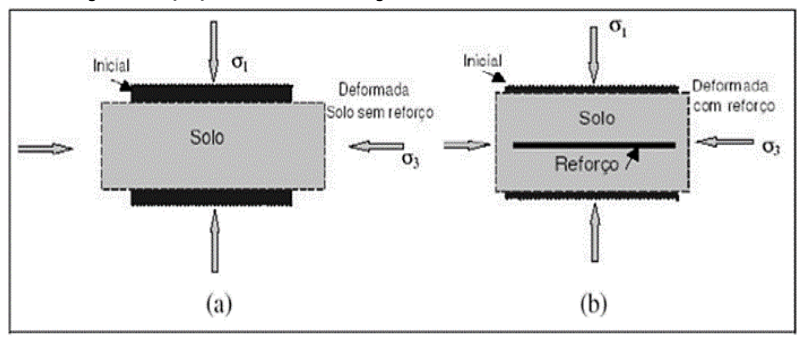

Fonte: Sieira, 2003 apud Maparagem (2017) 
Geralmente, os solos possuem elevada resistência a esforços de compressão, porém baixa resistência a esforços de tração. Quando uma massa de solo é carregada verticalmente, sofre deformações verticais de compressão e deformações laterais de expansão (tração). No entanto, com a introdução de reforços no aterro, os movimentos laterais são limitados pela reduzida deformabilidade do reforço (rigidez) (ANANIAS et al., 2013)

\subsubsection{Rigidez do reforço, deformação e ser- vicibilidade}

Os deslocamentos medidos (verticais e horizontais) e as deformações estimadas estão diretamente relacionados ao módulo de rigidez dos reforços (geossintéticos). Obras que envolvem carregamentos elevados e que apresentam limites restritos de deslocamentos, são particularmente situações que exigem o uso de reforços com elevada rigidez (BS 8006-1, 2010).

A deformação é inversamente proporcional à rigidez. Este aspecto é, portanto, decisivo na seleção do material de reforço a ser utilizado. $\mathrm{O}$ uso de reforços rígidos é recomendado para estruturas que devem apresentar pequenas deformações.

Ainda que o equilíbrio seja garantido e que não haja maiores riscos de ruptura, há que se definir limites de servicibilidade a serem respeitados. Estes limites dizem respeito diretamente à condição de operação adequada e conforto dos usuários, que por sua vez, são determinadas pelo desempenho da estrutura a longo prazo (BRUGGER; SILVA, 2012). Neste contexto, as obras de engenharia devem atender a critérios de funcionalidade e estética, além da garantia de uma segurança adequada ao colapso, na geotecnia, trata-se de atender aos requisitos do projeto, com o conceito definido como "servicibilidade" (do inglês serviceability).

Em geral, os limites de deformação do reforço por critérios de servicibilidade são definidos por normativas locais, e variam pouco de país para país no caso de estruturas de solo reforçado. No caso de contenção por- tantes e quaisquer estruturas em solo reforçado aplicados em obras de elevada responsabilidade, os valores de deformação permitida para os reforços são muito restritivos. A norma britânica (BS 8006, 2010), por exemplo, limita as deformações pós-construtivas nos reforços de estruturas portantes em apenas $0,5 \%$ para pontes e viadutos, e 1,0\% para em geral (BRUGGER; SILVA, 2012).

Para que sejam utilizadas geogrelhas de alta resistência, é necessário que se conheça as curvas de tensão-deformação (Figura 12) do material, e verifique o comportamento de deformação a curto e longo prazo (fluência). São recomendados que a energia de compactação deva ser grande, de modo a estabilizar a maior parcela das tensões (e das deformações) durante a compactação.

Figura 12. Modelo de curva tensão-deformação de geogrelhas Fortac de poliéster.

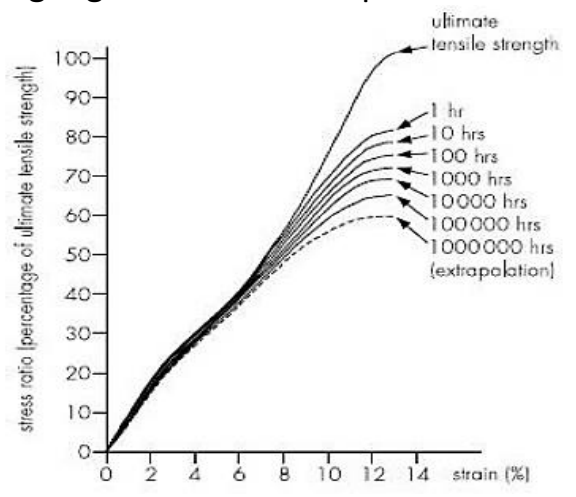

Fonte: BRUGGER e SILVA, (2012).

De acordo com Brugger e Silva, (2012) o acréscimo no alongamento especifico máximo entre o final da compactação e o final da construção da obra, deve ser menor do que $5 \%$. 0 acréscimo no alongamento especifico máximo entre o final da construção e a longo prazo deve ser menor do que $1 \%$ (a norma inglesa BS 8006 recomenda 1\% para contenções em geral, e 0,5\% para contenções portantes de viadutos e pontes).

\subsection{Obras Executadas no Brasil}

Existem no Brasil obras executadas em que o tabuleiro do viaduto se apoia sobre o aterro reforçado e não em fundação independente. 
Em Maringá, no Paraná, a prefeitura municipal com apoio do governo federal, investiu no rebaixamento da linha férrea que corta a região central da cidade. A primeira fase foram obras de $1,6 \mathrm{~km}$, e a segunda de $3,0 \mathrm{~km}$, e utilizados oitocentos mil metros quadrados de geogrelhas de poliéster com módulos de deformações entre 500 e $1100 \mathrm{kN} / \mathrm{m}$, para as contenções laterais de até

$10 \mathrm{~m}$ de altura de uma trincheira ferroviária projetada para isolar o tráfego ferroviário da região central da cidade (BRUGGER; SILVA, 2012).

As figuras 13, 14 e 15 que estão a seguir, apresentam detalhes da obra do viaduto portante executado em Maringá-PR. Através destas, é possível ter conhecimento da seção-tipo projeta, onde foi executada a fundação direta atuando sobre o solo reforçado com geossintético.

Figura 13. Seção-tipo dos viadutos portantes de Maringá.

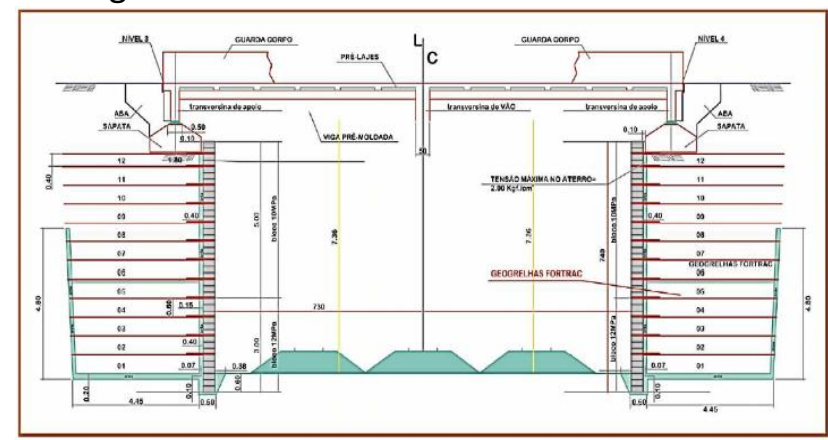

Fonte: Ruiz et al., (2018).

A execução da obra ocorreu com elevados índices de produtividade (superiores a $100 \mathrm{~m}^{2}$ de face em blocos executados por dia), utilizando o próprio solo local como material de aterro, sem limitar a operação da ferrovia e com estética muito atrativa. As Figuras apresentam o detalhe de apoio de viadutos portantes utilizados nesta obra como elementos de travessia da trincheira ferroviária pelo tráfego local (BRUGGER; SILVA, 2012).
Figura 14. Detalhe do apoio de um viaduto portante executado em Maringá-PR.

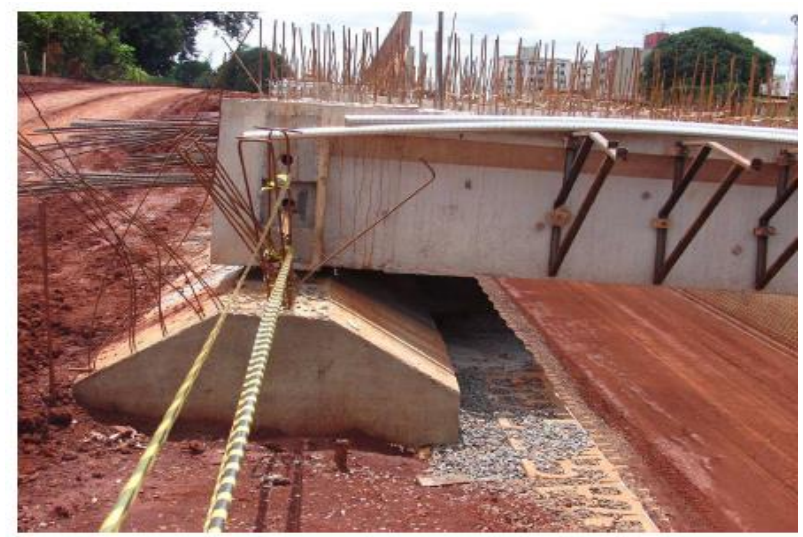

Fonte: BRUGGER e SILVA, (2012).

Figura 15. Colocação das vigas longitudinais prémoldadas.

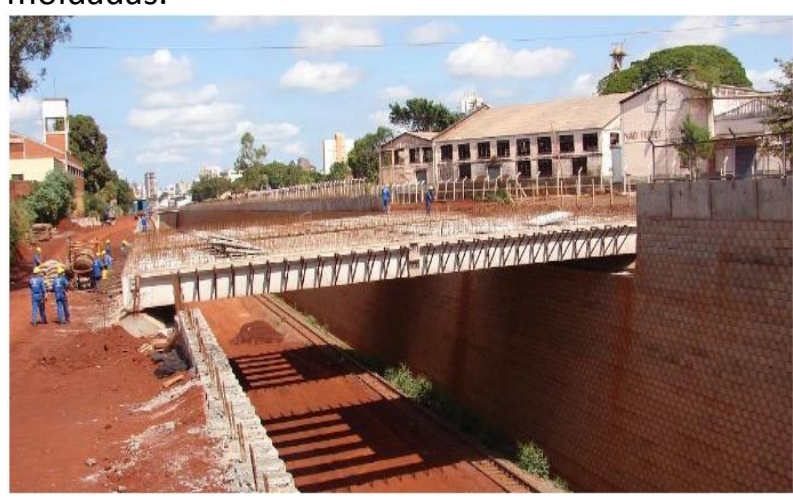

Fonte: Ruiz et al., (2018).

Com este método, evitou-se o custo de execução de fundações para a ponte ou viaduto, bem como, eventuais riscos de recalques diferenciais. As vantagens apresentadas por este tipo de solução para obras de contenção em encabeçamentos de pontes e viadutos portantes justifica o trabalho desenvolvido.

No município de Jaguaruna, Santa Catarina, foram projetados dois Muros Segmentais (face de blocos), posicionados um em frente ao outro, para cumprirem dupla finalidade cada um: conter os aterros na face frontal dos aterros viários e suportar o viaduto diretamente apoiado sobre as contenções, de suporte da estrutura do viaduto apoiado no topo do muro através de fundação direta (BRUGGER; SILVA, 2012).

As figuras 16 e 17 a seguir, apresentam detalhes do projeto dimensionado para a execução da obra no município de Jaguaruna, 
extraídos do projeto executivo em planta e posição do viaduto.

Figura 16. Vista em planta e posição do viaduto (projeto executivo).

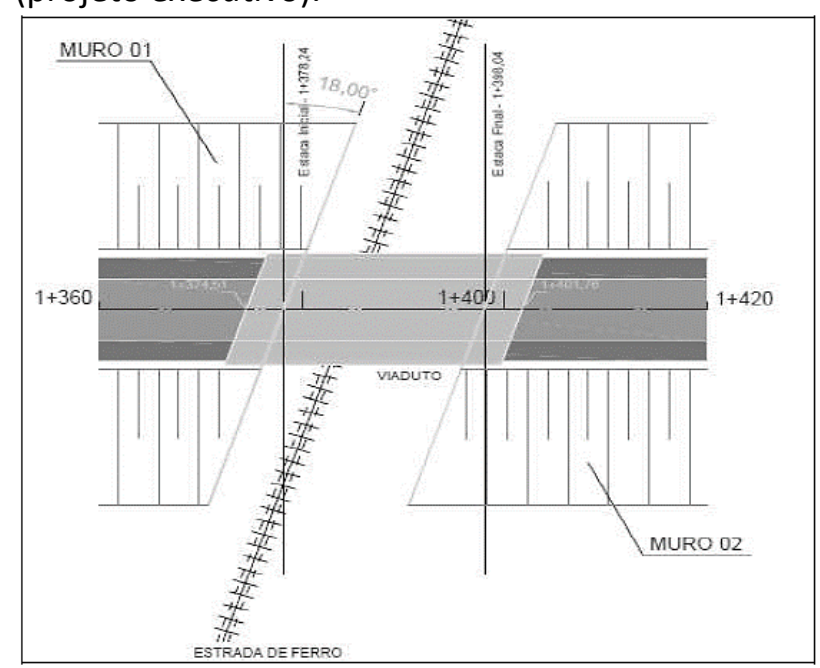

Fonte: BRUGGER e SILVA, (2012).

Os dois muros de encabeçamento estão distanciados de $20 \mathrm{~m}$ entre si, $6,2 \mathrm{~m}$ de altura livre e, adicionalmente, um embutimento de $1,5 \mathrm{~m}$. O dimensionamento foi a partir do método de rigidez relativa (Ehrlich e Mitchel, 1994). Foi construído utilizando-se geogrelhas Fortrac de filamentos de PVA, de elevada rigidez e baixa fluência, com deformação de ruptura inferior a $5 \%$. No total, foram utilizadas 8 camadas de geogrelha PVA de $200 \mathrm{kN} / \mathrm{m}$ de resistência nominal (120 $\mathrm{kN} / \mathrm{m}$ de carga de ruptura a longo prazo) e 7 de $110 \mathrm{kN} / \mathrm{m}$ de resistência nominal (65 $\mathrm{kN} / \mathrm{m}$ de carga de ruptura a longo prazo). As primeiras foram espaçadas de $60 \mathrm{~cm}$ e as demais de $40 \mathrm{~cm}$. Todas as camadas de reforço foram instaladas com $7 \mathrm{~m}$ de comprimento e conexão dupla na face, totalizando $8 \mathrm{~m}$ de comprimento para cada camada de reforço (BRUGGER; SILVA, 2012).
Figura 17. As built da seção executada e instrumentada (projeto executivo).

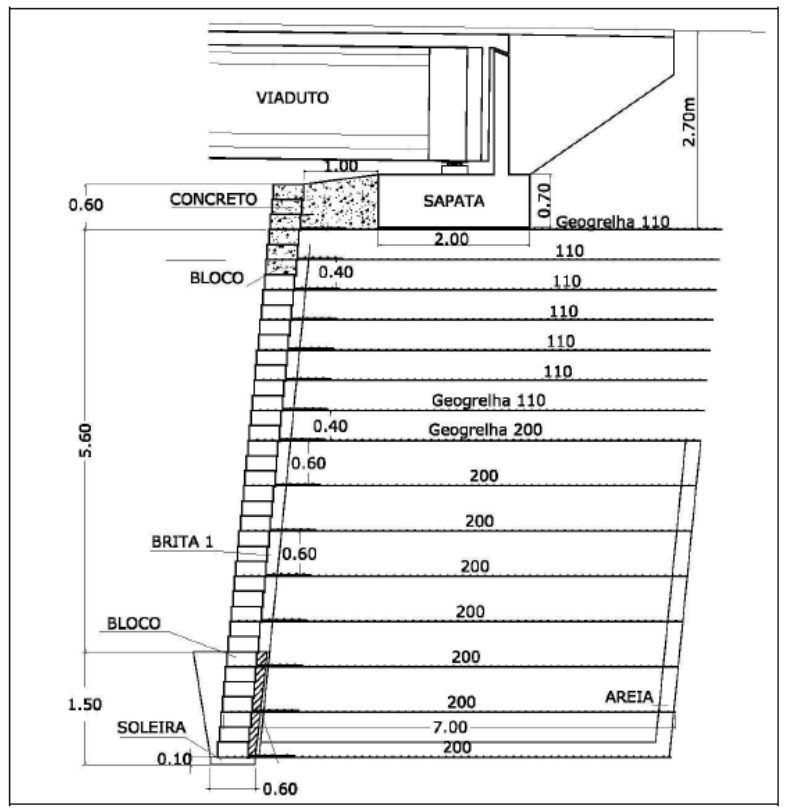

Fonte: BRUGGER e SILVA, (2012).

\section{CONSIDERAÇÕES FINAIS}

$O$ método de solo reforçado com geossintéticos demonstra que a utilização de geogrelhas de alta resistência, alto módulo e baixa fluência, aliados a uma compactação energética resultem em estruturas pouco deformáveis, que atendem aos requisitos de aspecto estético e funcionalidade, além de segurança ao colapso. $\mathrm{O}$ uso de reforços bastante rígidos é recomendado para estruturas que devem apresentar pequenas deformações.

A técnica de solo reforçado aplicadas como portantes (fundação direta) em encontros de pontes e viadutos mostrou-se, uma alternativa viável sob diversos aspectos: facilidade construtiva, boa estética, adequação geométrica e, também, sob o ponto de vista do comportamento da estrutura.

Sobre o aspecto de Servicibilidade, destaca-se a sua relevância em obras de estruturas de contenção, que quando são levados em conta os seus critérios, garante que a obra atenda aos níveis de estética e de comportamento ao longo prazo, evitando inclusive necessidade de reparos e manutenções futuras. Neste aspecto, as geogrelhas de PVA são mais rígidas que as de Poliéster, proporcionando-se como uma excelente alternativa de materiais de reforço de estruturas de con- 
tenção em solo reforçado, principalmente as obras de grandes responsabilidades como pontes e viadutos.

A alta resistência a tração, alto modulo de rigidez e baixa fluência, aliadas a uma compactação com energia próxima ao Proctor Normal, resultam em estruturas pouco deformáveis, que atendam a requisitos estéticos e de funcionalidade, além de segurança ao colapso para pontes e viadutos, de acordo com a norma britânica BS 8006 .

Para este método de obra com solo reforçado, é necessário que os materiais utilizados como reforço e solo sejam antecipadamente conhecidos ou especificados, também seja apurada a energia de compactação que será utilizada. Imprescindível para averiguação das deformações é o conhecimento das curvas de tensão-deformação das geogrelhas, bem como o desempenho ao longo do tempo (Fluência).

\section{REFERÊNCIAS}

ANANIAS, E. J.; TEIXEIRA, A. M.; DURAN, J. S. $O$ uso crescente de solos reforçados para contenções em áreas urbanas: uma ênfase aos 20 anos da solução Terramesh no Brasil. Artigo Científico. São Paulo - Jundiaí. 2013.

ANANIAS, E. J. ; TEXEIRA, A. M. ; DURAN, J. S. $O$ uso crescente de solos reforçados para contenções em áreas urbanas: uma ênfase aos 20 anos da solução Terramesh no Brasil. In: CONFERÊNCIA BRASILEIRA DE ESTABILIDADE DE ENCOSTAS, 5., 2009, São Paulo. Anais [...]. São Paulo, 2009.

AVESANI NETO, J. O.; HAYASHIDA, E. M. PEREIRA, V. R. G. Levantamento e comparação dos custos de diferentes soluções de estruturas de contenção em aterro. COBRAE 2013, Angra dos Reis, Rio de Janeiro. 2013.

BS 8006. Code of Practice for Strengthened and Reinforced Soils and Other Fills. British Standard, London, Inglaterra. 2010.

BRUGGER, P.J.;MONTEZ, F.T. Muros de contenção em solo reforçado com geogrelhas $e$ blocos segmentais., Porto Alegre: Geossintéticos, 2003.

BRUGGER, P. J.; SILVA, A. E. Muros em solo reforçado para obras hidráulicas. São Paulo: ABMS, 2009.

BRUGGER, P.J.; SILVA, A.E. Análise do comportamento de muro de contenção portante em solo reforçado a partir de monitoramento de campo. COBRAMSEG. Muro Terra e Portante. 2012.

MAPARAGEM, A. S. Estudo da interação solofitas poliméricas para uso em terra armada em solos problemáticos em áreas agrícolas e de mineração artesanal (garimpo). In: CONGRESSO LUSO-MOÇAMBICANO DE ENGENHARIA, 8., CONGRESSO DE ENGENHARIA DE MOÇAMBIQUE MAPUTO. 5., 2017. Anais [...]. Publ: INEGI/FEUP. 2017.

RUIZ, E. F.; MOTA, G. M.; FORTEZA, A. L. Solo reforçado com geogrelhas: Aplicações em obras de encontros de pontes e viadutos. Disponível em: http://igsbrasil.org.br/wpcontent/uploads/2017/12/CCO-2012-Soloreforçado-com-geogrelhas-aplicações-emobras-de-encontros-de-pontes-eviadutos.pdf. Acesso em: 01 de Outubro. 2018. 